\title{
Rompendo com a criminalidade: saída de jovens do tráfico de drogas em favelas na cidade do Rio de Janeiro
}

\author{
Stopping with the criminality: a way out of youths involved in traffic \\ of drugs in slums in the city of Rio de Janeiro
}

Zilah Vieira M eirelles ${ }^{1}$

Carlos M inayo Gomez ${ }^{1}$
${ }^{1}$ Escola Nacional de Saúde Pública, Fundação O swaldo Cruz. Rua Leopoldo Bulhões 1480 ,

Manguinhos. 21041-210

Rio deJaneiro RJ.

zmeirelles@terra.com.br
Abstract This article deals with the lives of young egress of drug traffic in the slums of the city of Rio de Janeiro. Its main objective is to examine the circumstances and the specific conditions that drive young peopleto abandon thisillegal work activity. Themethod used to collect data was the topical life story in order to find out how 30 youths, from seven slums, had got involved until their departure from the "movement". D ata shows that youths, entering trafficking, had an expectation of empowerment. With time, this attitude will wane, as they realize they are living with situations of betrayal, punishment and fear. The process for getting out occurs when the youth begins to question this type of work and sees other ways of life, more consistent with their aspirations. The facts conclude that when getting an early involvement in organized crime it leaves them physically and emotionally exhausted, as selling drugs is an ongoing confrontation through constant episodes of armed conflicts and arms dealing.

Key words Slum, Violence, Youths involved in traffic of drugs
Resumo 0 presente artigo aborda a vida de jovens egressos do tráfico de drogas nas favelas da cidade do Rio de Janeiro. Seu principal objetivo consiste em analisar as circunstâncias e condi ções específicas que impulsionam osjovensa abandonarem essa atividade, ilícita, de trabalho. 0 método utilizado para a coleta de dados foi a história de vida tópica que permitiu conhecer o percurso deentrada esaída detrinta jovens do tráfico, moradores de setefavelas. Os dados revelam que os jovens, ao entrarem para o tráfico, apresentam uma expectativa de encantamento, poder e dinheiro. Com o tempo, essa perspectiva vai desaparecendo devido às situações de traição, punição e medo. 0 processo de saída ocorre quando 0 jovem começa a questionar este estilo de trabalho e procura visualizar outras possibilidades devida, mais condizentes com as suas aspirações. Concluiu-se que o fato de os jovens estarem entrando precocemente no crime organizado leva-os a um desgaste físico e emocional, visto que a venda de drogas passou a ser um coadjuvante frente aos constantes episódios de conflitos armados e tráfico de armas. Palavras-chave Favela, Violência, Jovens egressos do tráfico de drogas 
Introdução

A cidade do Rio de Janeiro, desde 1994, lidera o ranking dos estados com maior número de homicídios na população jovem entre 15 e 24 anos de idade. Em 2004, esteíndiceatingiu 102,8 mortespor cada 100 mil habitantes, estando o tráfico de drogas associado a $90 \%$ desses homicídios ${ }^{1}$. As estatísticas refletem um cenário de intensa vulnerabilidadesocial, principalmente para al gunsjovens empobrecidos, os quais são usados na linha de frente de uma guerra entre o crime organizado e o Estado. Ao mesmo tempo, a ausência de políticas públicas mais efetivas torna o mercado varejista de drogas uma opção atraente para este grupo etário.

A violência urbana praticada e sofrida por jovens tem-se transformado em um grave problema na sociedade brasileira e, ao mesmo tempo, um desafio para a saúde pública. A década de oitenta trouxe enormes tensões sociais entre a população infanto-juvenil pobree a sociedade carioca; de um lado, as denúncias constantes de maus-tratos e abuso sexual com jovens internos no sistema da Funabem. De outro lado, o aumento progressivo da população jovem de ou na rua da cidade do Rio ${ }^{2}$. Logo, a dimensão que o tráfico de drogas estava tomando em al gumas favelas da cidade, inclusive com recrutamento de adolescentes para 0 seu "bando", passou despercebida, visto que a sociedade estava com o foco voltado para a questão do jovem pobreque se polarizava entre o confinamento institucional ea liberdadederua. Todavia, a dimensão do envolvimento desta população no tráfico de drogas somente teve atenção dos órgãos públicos no início desta década, quando os altos índices dehomicídios evidenciaram uma realidade cruel para este segmento populacional.

Os primeiros estudos sobre a participação de jovens no comércio varejista de drogas ilícitas, nas favelas do Rio de J aneiro, se reportam aos anos de 19803. Associava-se o aumento da violência urbana à adesão de jovens ao crime, que crescia de forma acelerada4. Em meados da década de noventa, os jovens de classe média também começaram a participar desse rentável mercado ${ }^{5}$ e, assim, o tráfico deixou de ser uma atividade exclusiva para pobres, negros e "favelados".

Estudos da O rganização Internacional do Trabalho ${ }^{6}$ apontam que a média de idade de jovens que entram para o tráfico vem diminuindo consideravelmente. $\mathrm{Na}$ década de noventa, a idade era entre 15 e 16 anos e, a partir do ano 2000, essa média se situa entre 12 e 13 anos. 0 aumento do número de adolescentes pode ser explicado, entre outros motivos, pelo fascínio que o clima de aven- tura e o porte de armas podem causar em garotos que crescem em áreas de conflito armado.

Por outro lado, a invisibilidade social também contribui para a permanência destes jovens no mundo do crime. $\mathrm{N}$ a busca de uma identidade social, os jovens manifestam o fascínio por status e por arma de fogo, o que lhes garante o reconhecimento e poder na favela onde vivem? ${ }^{7}$. Como afirma Athayde et al., a maneira que esses jovens encontram para serem notados é assumir a conduta de bandido;"o sujeito que não era visto, impõe-se a nós. Exige que tratemos como sujeito. Recupera a visibilidade, recompõem-secomo sujeito, seafirma e reconstrói" 8 .

Compreender essa trajetória de fascínio que alguns jovens incorporam através do mundo crimee, ao mesmo tempo, entender, por que um certo número desses jovens perdem 0 encanto pelo tráfico e conseguem romper com o crime organizado é o que propõe este artigo.

\section{Material emétodos}

0 estudo realizado foi de cunho qualitativo e optou-sepor utilizar a história devida tópica, em que se aborda determinados episódios da história do sujeito ${ }^{9}$. Para tanto, realizou-se entrevistas semiestruturadas com questões que visavam estimular a narração de quatro momentos distintos e complementares da vida dos jovens: 1) a pré-entrada no tráfico, visando identificar os fatores que potencializaram a inserção no tráfico dedrogas; 2) os processos de vida e trabalho durante sua permanência no crime organizado; 3) as principais razões que os levaram a sair do tráfico e 4) os mecanismos de apoio encontrados para essa transição. Cabe ressaltar que a ênfase deste artigo estará pautada no item três, ou seja, na análise das circunstâncias específicas que induziram e possi bilitaram a saída desses jovens da organização do tráfico varejista de drogas.

A pesquisa ocorreu em sete favelas das zonas norte e centro da região metropolitana da cidade do Rio de Janeiro. A escolha dos locais foi em função da possibilidade de acesso aos jovens egressos, uma vez que a autora vem realizado trabalho de intervenção social nesses espaços há vinte anos. $\mathrm{Na}$ seleção das favelas, adotou-se o critério de serem lugares que estão sob o julgo da mesma facção do crime organizado, o Terceiro Comando. A organização do tráfico de drogas varejista na cidade do Rio de Janeiro é dividida por três facções: o Comando Vermelho (CV), o Terceiro Comando (TC) e uma derivada dela, denominada Amigos dos 
Amigos (ADA). As facções são formadas por quadrilhas que controlam as rotas do mercado de drogas, assim como, frequentemente, o direito de ir e vir da população de uma determinada área ou re gião. Essas facções disputam os territórios das favelas, como forma de expandir seus negócios (domínio dos pontos de vendas de drogas), razão pela qual os moradores e, principalmente, osjovens, são proibidos decircular em áreas de comandos rivais ${ }^{10}$.

Participaram da pesquisa trinta jovens com idade entre 16 e 24 anos que ingressaram no mercado do tráfico de drogas a partir do ano de 1995. Para a seleção do grupo: (1) optou-se por entrevistar apenas os rapazes, tendo em vista que eles são em número muito mais elevado que as meninas nesse tipo de atividade; (2) trabalhou-se com o critério de ao menos um ano de envolvimento com o tráfico para que se dispusesse de uma expe riência mais densa por parte dos entrevistados.

As entrevistas ocorreram nas dependências de uma organização não-governamental localizada no bairro de Vila I sabel. Os jovens se mostravam de forma bastante cordial e tímida, ainda que os recém-saídos do tráfico apresentassem um vocabulário com palavras e gírias próprias do "movimento". Frequentemente, neste artigo, se utiliza o termo "movimento" para designar o mercado varejista informal e ilegal de drogas na cidade ${ }^{11}$, tendo em vista ser esta a denominação usada pelos próprios participantes.

0 contato inicial para realização da pesquisa foi com João, jovem de 21 anos com um percurso longo no tráfico de drogas. Entrou e saiu duas vezes do movimento. Sua última retirada foi há dois anos, quando ocupava a posição de gerentee coordenava um grupo expressivo de comandados. O seu jeito de ser, sempre muito comunicativo, associado a sua função de poder no tráfico, permitiu-Ihe criar uma imagem de liderança e, mesmo não estando mais no movimento, continua sendo uma figura de referência, principalmente para os de menor idade.

Os rapazes que foram convocados para a pesquisa chegavam sempreao local da entrevista acompanhados por outros egressos, o que permitiu em alguns momentos - após as entrevistas - manter uma conversa informal e coletiva com todos. Ge rou-se inclusive uma expectativa de apoio que se traduziu numa proposta de intervenção social, articulada com o Núcleo de Estudos da Saúde do Adolescente da Universidade do Estado do Rio de Janeiro e a organização não-governamental Instituto Social Dom Pixote.

A pesquisa foi submetida ao Comitê de Ética da Escola Nacional de Saúde Pública da Fundação
O swaldo Cruz e devidamente aprovada com a recomendação de não utilizar o termo de consentimento e livre esclarecimento, por conta do risco aos sujeitos da pesquisa.

\section{Resultadosediscussão}

Caracterização do grupo de estudo

Apesar da pesquisa ter sido qualitativa, utilizou-se alguns dados quantitativos para uma meIhor compreensão do perfil dos jovens estudados.

Os trinta entrevistados apresentam características bastante semelhantese, ao mesmo tempo, singulares em al gumas questões que personificam seus estilos de vida. Dezoito deles, ao saírem do tráfico, voltaram a conviver regularmentecom suas famílias, dez passaram a viver com suas parceiras e dois, com amigos. Evidencia-se que o espaço da favela é o mesmo ambiente de atuação do tráfico. Logo, de modo geral, dificilmente os jovens engajados no tráfico nas favelas perdem o vínculo familiar, embora, muitas vezes, sejam impedidos de morar com a família por terem que ficar disponíveis para as atividades do tráfico, ou seja, em "estado de alerta" contra invasões ou confrontos policiais.

Evidencia-se que a totalidade dos jovens entrevistados, antes de entrar para o movimento, morava somente com suas mães e outros familiares. A ausência do pai éum traço marcantena história de suas vidas, sendo interpretada por eles como uma perda significativa na construção de sua identidade, como relatam alguns jovens: $M$ eu pai nunca quis saber de mim (Cristóvão, 17a); Sempre senti falta de ter um pai pra conversar sobre os problemas da vida (Fabio, 22a).

Em relação ao nível de escolaridade, dois concluíram o ensino fundamental, 26 não 0 concluíram e dois estão finalizando o ensino médio (um por motivo de ascensão profissional e o outro por apoio familiar). Quanto à situação laboral, dezoito jovens não trabalhavam no momento da entrevista e doze realizavam algum tipo de atividade (três no mercado formal e nove no mercado informal). São jovens que abandonaram muito cedo a escola para se envolverem com o tráfico, onde permaneceram, em média, de seis a sete anos. Por causa da baixa escolaridade, esses jovens enfrentam grandes dificuldades para encontrar emprego. Além disso, a incorporação de linguagem e hábitos próprios da criminalidade, ao longo desses anos, representa mais um agravante tanto para o seu processo de socialização quanto para a sua inserção no mundo do trabalho ${ }^{12}$. 
Do grupo entrevistado, oito jovens não residiam mais na mesma favela de origem. Conforme relataram, fica difícil permanecer no mesmo espaço físico: Tem que ser cabeça forte, se não começa tudo de novo e tu nem sente, pois os próprios amigos ficam sempre em torno de você. Aí fica, segura isso, guarda pra mim. A alternativa é colocar uma marmita em baixo do braço eralar peito ou, do contrário, você sai da comunidade (Claudio, 23a). Continuar na favela supõe também enfrentar momentos de grande insegurança: É muito forte, é muito difícil. A polícia entra e tu fica todo nervoso, tu acha quevão te pegar e, aí, tu não tem mais arma na mão pra se defender de qualquer parada, entendeu? Tu fica muito maluco, setu não tiver uma pessoa boa do lado, tu faz besteira ( $M$ arcelo, 19a).

Nos depoimentos, os entrevistados acrescentam três motivos para se retirarem da cena onde viveram até então: a) os próprios "colegas" do tráfico estão sempre circulando por perto na tentativa de seduzir o jovem a retornar para o movimento. Além disso, eles tendem a olhar o que sai com uma certa desconfiança, porque ele tem informações privilegiadas sobre o tráfico e a geografia do local e pode ser atraído pela facção rival; b) algumas pessoas da comunidade não acreditam que 0 jovem possa "dar a volta por cima"; c) se há al gum episódio de roubo na comunidade, o jovem é o primeiro a ser visto como suspeito.

Assim, procurar outros espaços constitui uma tentativa de buscar novas relações sociais, outros significados para suas vidas, longe do confinamento imposto pelas leis do tráfico ${ }^{13}$. A pesar da importância de se afastarem dos locais do movimento e de manifestarem desejo ou necessidade de sair da favela, diversos jovens não encontram apoio social para isso, seja por parte da família que poderia acolhêlos ou dos próprios amigos: $\mathrm{N}$ em todos conseguem ir embora da comunidade. A família que mora longe fica com medo de te acolher. $N$ ão sabe o que você fez. Se vai ter alguma complicação, algum problema. Se vai ter alguém atrás de você, entendeu? (M aurício, 18a). Além disso, esses rapazes têm que encontrar um local controlado pela mesma facção de sua comunidade deorigem. Caso optem por uma comunidade de facção rival, podem correr risco de vida.

No que concerne à função exercida na hierarquia do tráfico no momento do seu afastamento, dezesseis eram olheiros (vigias situados em pontos estratégicos ao redor da "boca de fumo", munidos de walkie talkies e fogos de artifícios ou armas de pequeno calibre com pouca munição, para alertar os colegas sobre a chegada da polícia ou de grupos rivais); oito exerciam a função de vapores (encar- regados de distribuir, vender e recolher o dinheiro das drogas); três atuavam como soldados (armados constantemente para defender a favela, caso houvesse invasão do grupo rival ou entrada da policia); dois jovens eram seguranças do gerente ou do chefe do tráfico na favela, carregando geralmente as armas mais sofisticadas e pesadas; um jovem trabalhava como gerente (administra os pontos devenda dedrogas na favela, popularmente conhecida como "boca de fumo"). 0 gerente exerce uma função de poder e destaque na hierarquia do tráfico, inclusive merecedora de melhor remuneração.

D os entrevistados, 21 declararam que faziam uso regular de maconha, cocaína ou loló, quando estavam no tráfico, sendo que onzeainda continuavam a consumir, sete eram usuários ocasionais de maconha e dois não faziam uso de nenhum tipo de droga. Desses jovens, seis participaram de assal to à mão armada, dois deles tendo sido presos e fichados; quatro foram presos e fichados em batida policial nas favelas e um foi preso por motivo de briga na rua. Os outros não têm ficha policial. Cinco dos rapazes disseram que cometeram homicídio. Os demais não sabem se mataram alguém, apenas mencionaram ter participado de tiroteios, sem nenhum treinamento prévio para a utilização de uma arma: Os caras colocam a arma na mão da gente ea gente sai atirando. 0 treino éa partir do dia a dia. A gente aprende a atirar na hora da guerra ( $M$ arco, 22a).

Cabe destacar-se a idade prematura de entrada desses jovens no tráfico de drogas. A faixa etária de maior inserção situa-se em torno de dez a catorze anos, inclusive dos entrevistados, dois tinham aderido ao movimento com idade inferior a 10 anos. Em relação à saída, a maior parte deles 0 fez entre quinze e vinte anos. Constata-se que 0 maior número de jovens (15) permaneceu no tráfico de seis a sete anos, doze ficaram de quatro cinco anos e três, de um a três anos.

\section{Situação de ruptura pelos próprios jovens}

A maioria dos jovens, no momento das entrevistas, estava já afastada do tráfico em torno de um a três anos. Os argumentos expressos sobre a saída do tráfico apresentam diferenças significativas relacionadas ao tempo transcorrido desde o desligamento. Os mais antigos argumentam que o processo de trabalho do tráfico tem passado por mudanças profundas, na medida que entram dando oportunidade aos jovens de usá-las: Antigamente não era todo jovem que colocava a mão numa arma. $\mathrm{H}$ oje, qualquer garoto tem uma arma. Fica tudo se 
sentindo [importante] (Cláudio, 23a). Os episódios de conflitos armados aumentaram entre as quadrilhas rivais e, consequentemente, a dinâmica interna de funcionamento do tráfico sofreu transformações: Agora não é só vender bagulho [drogas], é estar na guerra também. Em decorrência dessa situação, o tráfico de armas veio consolidar as quadriIhas do crime que atuam no varejo nas favelas e comunidades pobres, intensificando a violência em níveis insuportáveis ${ }^{14}$. Essa experiência tem repercussões sobre a subjetividade dos jovens que, segundo os entrevistados, passam a estabelecer relações interpessoais e sociais mais violentas.

Os rapazes comentam que, anos atrás, o jovem dificilmente manifestava o desejo de sair do movimento. H oje, essa situação mudou, mas para essa vontade se concretizar, ele precisa de apoio: Sozinho tu não sai, al guém tem queajudar etem que ser uma pessoa de respeito na comunidade pro chefe ouvir. Tivemuita sorte, agradeço a D eus (Felipe21a). Entre os principais motivos que levaram à saída dos mais antigos, encontram-se o apoio de grupos religiosos; a incapacidade física provocada por um tiro e perturbações mentais por terem sido torturados ou traídos por um amigo.

No grupo de jovens que se desligou em períodos mais recentes, os motivos maisfrequentemente mencionados foram o medo de morrer; as tensões físicas eemocionais causadas pel os constantes conflitos armados; as ameaças de castigos e torturas e a frustração da expectativa de obterem grandes ganhos econômicos (Tabela 1).

A saída dos jovens das quadrilhas do tráfico, em grande medida, guarda relação com suas aspirações na hora de entrar nessa "rede" e o descompasso entre os sonhos alimentados e as possibilidades objetivas de realizá-los. Em geral, todos os entrevistados revelaram que não existe um único motivo, mas uma variedade de situações que vão empurrando o jovem a entrar e posteriormente a sair do tráfico de drogas: São as decepções da vida que leva a gentepra isso, repetem vários. A inserção no tráfico de drogas não ocorre apenas para alcançar ganhos econômicos, como frequentemente se propaga, mas, particularmente, para alcançar ganhos simbólicos: A gente não pensa muito, não. Pra quê? Tem dinheiro, mulher, prestígio, metal [arma], bagulho [droga] a toda hora. Os jovens buscam auto-estima, respeito, visibilidade social. São fascinados por uma "subcultura viril" propiciada pelas armas, que aparentemente compensa a vulnerabilidade desses joven $\mathbf{s}^{15}$.

Essa mesma lógica multicausal procede quando um jovem se dispõe a sair dessa redeilícita, fundado em razões que vão sendo construídas ao longo do seu percurso no movimento. Ele vai vivendo situações limites, frustrações, punições, traições, que despertam nele gradualmente o desejo de romper com o caminho que escolheu: Você vai sacando que não énada daquilo. É muita ralação pra muito pouco. $\mathrm{N} \mathrm{em}$ todo mundo tem a sortedesedar bem (Caio, 22a). A sequência de decepções aparece claramente na experiência vivida por Gustavo: M eu amigo morreu do meu lado num tiroteio com a polícia, o sangue dele espirou em mim. Depois fui traído por um amigo, quase virei churrasquinho de pneu. Quando o dono do morro morreu, eu fiquei desprotegido. Sabe como é, vem outro chefeeeleforma outro bonde[ grupo]. Fiquei fora e perdi meu posto de segurança, me colocaram pra ser olheiro, aí fiquei bolado [revoltado] e resolvi cair fora (Gustavo 23a).

O sentimento de frustração por não conseguir destacar-seno mundo do crimeéum ponto crucial. Quando ingressam, têm expectativas de levar uma

Tabela 1. Jovens no tráfico de drogas: motivos de entrada e saída.

\begin{tabular}{lrlr}
\hline \multicolumn{1}{c}{ Motivos de entrada } & $\mathrm{f}$ & \multicolumn{1}{c}{ M otivos de saída } & $\mathrm{f}$ \\
\hline Perspectiva de ganhos econômicos & 16 & M edo de morrer por traição ou conflito armado & 20 \\
Desejo de bens e consumo & 12 & Foi traído pelo seu grupo do tráfico & 17 \\
Possibilidade de conquistar mulheres & 12 & Ameaças de castigo e tortura por traição ou vacilo & 9 \\
Status e poder pelo porte de arma & 8 & Frustração de expectativas econômicas & 9 \\
Vingança por morte de alguém & 6 & Perspectiva de constituir família & 4 \\
Proteção contra grupo rival & 6 & Iniciação religiosa (protestante) & 4 \\
Sem um motivo aparente & 3 & Incapacidade física e mental (levou tiro) & 2 \\
Sem esperança na vida & 2 & Não se adaptou ao mundo do crime & 2 \\
Revolta no seu âmbito familiar & 2 & Desejo em ter seu próprio negócio & 1 \\
\hline
\end{tabular}


vida farta de aventura, dinheiro emulheres. Com o tempo, eles percebem que estar no tráfico É dureza. Tem que ficar ligado o tempo todo, se não dança. Os membros das quadrilhas estão sempre submetidos a rotinas rígidas eseveras: 0 scarasmandam em você o tempo todo. 0 dinheiro, para a maioria, é pouco e as mulheres mais bonitas são para os traficantes que ocupam posições privilegiadas no movimento: As mel hores mulheres são para os manda-chuvas [gerentes e chefes], que podem pagar mais. Dão mais vantagensa elas. Como já se relatou, dos entrevistados, dezesseis olheiros, ou seja, estavam numa posição de pouco ganho e de grande tensão, podendo pagar com a vida, se falhar: Se tu não fica ligado, na entrada da comunidade, tu pode até morrer como foi o caso do P., que dormiu enão viu a polícia entrar. Por causa disso, o morro perdeu muito bagulho [droga] e metal [arma] (Caio, 17a).

0 processo dedesencanto decorredeacordo com os episódios acumulados de frustração das expectativas específicas de cada jovem. Porém, os entrevistados relataram que a decepção por ganhar pouco dinheiro é um traço comum entre os rapazes do movimento, o que alimenta a vontade de subir de posto. Por isso, a probabilidade de ascender na hierarquia do tráfico acarreta, muitas vezes, eventos de traição entre os membros do grupo. Como muitos não conseguem se elevar na escala do movimento, começam a ficar com sua auto-estima comprome tida. 0 baixo status significa muito empenho, pouco dinheiro e pouco poder de se relacionar socialmente na comunidade: A galera só te respeita porque tu tem dinheiro e uma arma na mão. U ma vez frustrados, alguns jovens já não se sentem com tanta disposição para enfrentar os momentos de grande tensão, de conflito armado na comunidade. 0 seu "sentimento de pertença" ao mundo do tráfico fica enfraquecido: Pô, semprechegava junto nas situações e nunca tive oportunidade. $\mathrm{N}$ unca fui puxa-saco pra subir na parada (Guilherme, 19a).

No entanto, enquanto fazem parte das quadriIhas, os jovens não podem recuar. É uma questão de matar ou morrer. 0 clima de guerra exige concentração, resistênciafísica eemocional. É frequente que os traficantes fiquem dias sem comer e dormir, escondidos nas vielas da favela. Neste momento, circunstancialmente, a comunidade deixa de ser um lugar privado e passa a ser um local público ${ }^{16}$. Eles vivem como fugitivos, dentro do seu espaço comunitário, quando "o bicho tá pegando", expressão utilizada tanto pelos rapazes do tráfico quanto pelos moradores para designar que o clima está tenso na comunidade.

Os momentos de confronto geram nos jovens um grandedesgastefísico eemocional, especialmen- te para os que entram com pouca idade e manifestam pouca capacidade de resistência: É muita adrenalina! Eu já escapei demorrer várias vezes. Eu acho que nem a morte gosta de mim. Ao escapar da morte, o jovem tem uma falsa percepção de um poder sobre a vida, capaz de levá-lo a acreditar que pode ousar, no próximo conflito. Esses sentimentos de onipotência repousam sobrea condição do ser adolescente que vive momentos de transição, de formação e ganhos, de necessidades de afirmação e de muitos desarranjos e inadequações, que o impulsionam para atitudes de heroísmo e coragem, sem a consciência exata dos perigos que o cerca ${ }^{17}$.

Essa mistura de sentimentos de poder e de vulnerabilidade potencializa os desgastes. 0 jovem sabe que não pode errar e que, caso vacile, pagará com a vida, o que geralmente ocorre precedido de torturas aterrorizantes. 0 medo de ser torturado e morto é um ponto que coloca os jovens em estado permanente de tensão. Três situações no processo de trabalho do tráfico configuram maiores chances dessas crueldades acontecer: 1) perder a mercadoria (droga) ou o metal (arma) principalmente quando a polícia entra na favela; 2 ) dormir durante 0 seu turno de olheiro e não antever possíveis ameaças; 3) errar na prestação de contas do dinheiro da venda droga. Algumas vezes, os jovens sofrem sabotagem dos próprios colegas, por motivos de concorrência interna, deixando-os em circunstâncias difíceis peranteo chefe do tráfico local.

$A$ traição éum aspecto marcantenos relatos dos entrevistados. Os episódios constantes de violência são por eles explicados pela falta de confiança entre colegas do grupo, por sentimentos de inveja pela ascensão de alguém no movimento ou por ciúmes pelo modo de alguém (alvo de traição) relacionarse com o chefe ou outra pessoa de poder no tráfico. Dependendo do tipo dedenúncia, o jovem pode ser castigado com agressão física ou com arma de fogo e, até mesmo, assassinado: A gente vai vendo muitas coisas, muita covardia. Do nada você tá conversando com um amigo, aí amanhã eletá traindo você, porque ele quer aparecer pro dono do morro. Ele quer tederrubar pra ficar no teu lugar (Paulo, 22a).

Já vi muito moleque morrer por traição. Fizeram isso comigo várias vezes. Sou malandro e sempre saquei esses lances. Só que eu fui começando a ficar com medo porque teve uma vez que eu quase fui parar no microondas [buraco no chão onde a pessoa é jogada e sobre ela ateado fogo]. Isso pra mim foi um susto, um despertar (Sandro, 18a).

A consciência da morte passa a ser uma experiência existencial muito forte para esses jovens. Eles tomam consciência que são seres finitos e têm limites. Seus ol hos se abrem para um novo enten- 
dimento da vida: Aí foi muito forte, pensei que ia morrer. Fiquei muito tempo bolado. $\mathrm{N}$ ão conseguia dormir mais direito e não conseguia me concentrar. Ficava com medo de morrer.

Em suma, uma gama de circunstâncias que conspira positivamente para a ruptura de um jovem com a quadrilha na qual entrou. 0 que antes representava encanto, com o tempo passa a representar desencanto e, assim, nasceà vontade de" $p u-$ lar fora". Contudo, todos ressaltam que, uma vez dentro, não é fácil sair. Quando um deles inicia o rompimento interior, geralmente sente-se sozinho e frágil para enfrentar uma decisão. Alguns começam a procurar, ao seu redor, pessoas que possam intermediar esse difícil caminho. Geralmente, os mediadores são indivíduos da própria comunidade que sempre estiveram próximos do jovem de uma maneira ou de outra, fazendo parte de seu contexto familiar, social e compondo para ele uma rede de proteção.

\section{Dificuldades e dilemas para a ruptura}

A possibilidade de sair ou não do movimento também depende do tipo de facção a que o jovem pertence. $\mathrm{O}$ Comando Vermelho (CV) tende a ter leis rígidas eseveras. Dificilmenteum jovem consegue deixar o grupo. Salvo al gumas exceções, como, por exemplo, ser parente ou protegido de algum chefe do próprio $\mathrm{CV}$, mesmo não sendo da mesma comunidade: $\mathrm{Na}$ comunidade do Barranco, quando era Comando Vermelho, o garoto que me traiu não foi morto por causa de que era afilhado do chefão do morro tal. Os entrevistados atribuem essa rigidez ao fato das favelas serem comandadas por chefes sem representatividadena comunidade, porquenão nasceram ali, não são "crias" do lugar. No Terceiro Comando (TC), as regras são mais flexíveis, pois geralmente as favelas são chefiadas por pessoas nascidas e criadas na própria comunidade e mantêm um sentimento maior de lealdade, tanto pelas pessoas quanto pelo local. Por exemplo, João, que ocupava o cargo de gerente do tráfico na facção $T C$, teve permissão para sair, porque é um exímio intérprete do samba ea cultura do carnaval é parte integrante da identidade da favela em que vive.

Os enredos, ou seja, as histórias contadas pelos jovens ou por aquele que vai até o chefe intermediar a sua saída geralmente envolvem o sentido da família e da educação: A família está sofrendo muito, Ele está querendo voltar a estudar, Ele quer casar e sair dessa vida. As decisões, no entanto, seguem critérios bastante subjetivos. Os entrevistados narram que o laço de afetividade do chefe com o jovem conta bastante na hora de decidir. É im- portante para quem vai intermediar a negociação entender a personalidade do líder e criar estratégias efetivas de convencimento. Os jovens comentam alguns casos esclarecedores: Eu conheço um mol eque que o dono [chefe do tráfico] permitiu que ele saísse por que ele tá pegando a sobrinha dele e a garota está grávida. Isso foi malandragem dele (Fernando, 19a).

Quando meu tio foi falar com o chefe, ele disse assim: "éengraçado quando eles entram ninguém vem aqui, agora pra sair vem todo mundo". A sorte que meu tio conseguiu falar bacana com ele (H ugo, 23a).

Ao obter o salvo-conduto, o rapaz vive um período transitório de insegurança e medo, pois sua saída não é imediata. É obrigado a passar por um tempo ainda em atividade. Esse tempo será maior ou menor dependendo do seu histórico no movimento. Elenão pode ser visto como "vacilão", como alguém capaz de se transformar num " $X-9$ " (traidor). Não pode dever dinheiro por consumo de droga, por perda de mercadoria (droga e arma) ou por outra razão similar. Em suma, não pode ter nenhum tipo de dívida, nem monetária nem moral, com a boca-de-fumo. 0 único caso em que o jovem é convidado a sair é quando, após um período deatuação no tráfico, não consegueacompanhar com destreza, valentia e destemor as atividades requeridas pelo movimento.

$\mathrm{N}$ a realidade, cada jovem tem o seu ritmo de saída, de rompimento com tráfico. Não basta ter o salvo-conduto para mudar a vida. Esse processo élento, complexo e sofrido. Vai depender de como esse jovem vai ser amparado, a partir do instante em que larga a arma, seja por pessoas ou por redes sociais. 0 caso émais complicado quando o jovem faz uso de drogas, pois pressupõe que ele tenha dinheiro para manter o vício. Como, geralmente, o rapaz não dispõe de recursos, pode acabar aproximando-se do seu antigo grupo para conseguir a droga e, assim, retornar. Consequentemente, o caminho da reinserção social é difícil.

Em resumo, a vida dos jovens que romperam com o tráfico é marcada por circunstâncias de grande vulnerabilidade. Para seter uma dimensão dessa fragilidade, no decorrer do trabal ho de campo, três jovens que estavam afastados do tráfico num período inferior a um ano retornaram ao mundo do crime. Um deles confessou: Eu tentei, tentei muito, mas não deu. É melhor eu ficar nessa vida que eu já conheço como ela é. 0 medo do desconhecido, do que vai encontrar fora da comunidade, aliado à falta de preparo, de apoio e de uma mediação consistente de proteção constitui grandes empecilhos, dificultando a ruptura com essa carreira tão dura e cruel. 
Uma questão se impõe: como levar a vida sem depender do tráfico? Não se trata apenas da dependência econômica, é também de identidade. Como transitar na comunidade sem o status e 0 poder, conferidos normalmente pelo tráfico? É ne cessário que o jovem tenha a oportunidade de vivenciar novas maneiras de se colocar no mundo e de se relacionar com outras pessoas fora do ambiente da marginalidade, da ilegalidade e do "poder de fogo da violência" - onde quase tudo se resolve com uma arma na mão.

O jovem egresso demanda apoio psicossocial, ele necessita reelaborar pensamentos, condutas, sentimentos evalores ${ }^{18}$. Para tanto, é prementeque a rede de apoio que sustentou a interlocução de saída do jovem do tráfico continue buscando, fora da comunidade, outras pessoas que possam ser incorporadas no processo de ajuda, ou seja, de cidadania deste jovem.

\section{Conclusões}

Sem dúvida, o tráfico de drogas confere aos jovens um pseudo status de poder, cativando-os a viver num contexto que muito se "expressa na exacerbação do ethos da masculinidade ${ }^{19}$. Esse mundo que não éde "ganhos fáceis", étambém um universo de atrocidades, ameaçando a vida desses rapazes em idade tão precoce.

0 estudo procurou desvendar algumas questões vividas pelos jovens no contexto do mercado do tráfico de drogas, com vistas a ampliar o debate sobre aqueles que perderam o encanto pelas atividades do tráfico e romperam com ele. Embora difíceis, suas trajetórias mostram que é possível a ruptura, quando essas pessoas, munidas de vontade, expectativas esonhos, procuram mediações eestratégias detransformação. As dificuldades reais de mudança e as possibilidades de retorno ao crimeficaram patentes. Os casos de retorno ou recaída de jovens que não vêem outro caminho a não ser o que já trilharam são emblemáticos para se discutir as necessidades de apoio e de referências fortes no seu meio social.

Buscou-se também dar relevância às experiências impactantes que marcaram a vida desses jovens, sobretudo o seu confronto com a morte e com a crueldade humana. Q ualquer projeto defuturo, sem dúvida, terá como pano de fundo tais vivências. $M$ ais que nunca, os egressos do tráfico precisam de uma rede de proteção social em torno de si, para amparar e tornar realidade sua enorme vontade de dar uma virada na vida, de olhar, pensar e sentir o mundo com outros valores e conceitos e, acima de tudo, descobrir que podem novamente sonhar.

\section{Colaboradores}

ZV M eirelles trabal hou na coleta e análise dos dados, bem como na redação do manuscrito. CM Gomez participou da interpretação dos resultados e da elaboração da versão final. 


\section{Referências}

1. Waiselfisz JJ. Mapa da violência dos municípios brasileiros. Brasília: Ministério da Saúde; 2007.

2. Centro de Estudos e Pesquisas em Educação, Cultura e Ação Comunitária. Guia de ações complementares à escola para crianças e adolescentes. 2a ed. São Paulo: Cempec/Unicef; 2001.

3. Zaluar A. Máquina e a revolta. Rio de Janeiro: Brasiliense; 1980.

4. Velho $G$, Alvito $M$, organizadores. Cidadania e violência. Rio de Janeiro: FGV; 1996.

5. Fiuza G. Meu nome não é Johnny. Rio de Janeiro: Record; 2004.

6. Silva SS, Urani A, organizadores. Crianças no narcotráfico: um diagnóstico rápido. Braślia: M inistério do Trabalho e Emprego/Organização Internacional do Trabalho; 2006.

7. Barreto L, Ribeiro M, Passos N. Vida bandida: figurantes na sociedade, protagonistas na mídia. In: Anais do XXX Congresso Brasileiro de Ciências da Comunicação; 2007; São Paulo.

8. Athayde C, Soares LE, MV Bill. Cabeça de porco. Rio de Janeiro: Objetiva; 2005. p. 215.

9. M inayo MCS. 0 desafio do conhecimento: pesquisa qualitativa em saúde. 8a ed. São Paulo: Hucitec; 2004.

10. Misse M. Malandros, marginais e vagabundos: acumulação social da violência no Rio de Janeiro [tese]. Rio de Janeiro (RJ): Iuperj; 1999.

11. Rafael A. Um abraço para todos os amigos: algumas considerações sobre o tráfico de drogas no Rio de janeiro. Niterói: EDUFF; 1998.
12. M eirelles ZV. Vida e trabalho de adolescentes no narcotráfico numa favela do Rio de Janeiro [dissertação]. Rio de Janeiro (RJ): Escola Nacional de Saúde Pública, Fundação Oswaldo Cruz; 1998.

13. Zamora $M H$. Confinamento, sociabilidade e violência nas favelas cariocas [tese]. Rio de Janeiro (RJ): Pontifica Universidade Católica do Rio de Janeiro; 1999.

14. M isse M, Lima KR. Crime e violência no Brasil contemporâneo: estudos de sociologia do crime e da violência urbana. Rio de Janeiro: Lumen Juris; 2006.

15. Zaluar A. Integração perversa: pobreza e tráfico de drogas. Rio de Janeiro: FGV; 2004.

16. Nobre C. Direto do front: notas sobre reportagem e narcotráfico no Rio de Janeiro. Cadernos Alceu 2005; 6(11):104-119.

17. Berastury A, Knobel M. Adolescência normal. 9a ed. Porto Alegre: Artes M édicas; 1991.

18. Fernandes NCBB, Oliveira AC, organizadores. Violência contra crianças e adolescentes: redes de proteção e responsabilização. Rio de Janeiro: Nova Pesquisa e Assessoria em Comunicação; 2007.

19. Zaluar A. Condomínio do diabo. Rio de Janeiro: UFRJ; 1995.

Artigo apresentado em 19/02/2008

Aprovado em 06/03/2008

Versão final apresentada em 05/05/2008 